\title{
Blockade of Neuronal Activity During Hippocampal Development Produces a Chronic Focal Epilepsy in the Rat
}

\author{
Cynthia D. Galvan,, ${ }^{1,2}$ Richard A. Hrachovy, ${ }^{4,5}$ Karen L. Smith, ${ }^{1,3}$ and John W. Swann ${ }^{1,2,3}$ \\ ${ }^{1}$ The Cain Foundation Laboratories, 2 Division of Neuroscience, ${ }^{3}$ Department of Pediatrics, and ${ }^{4}$ Department of Neurology, \\ Baylor College of Medicine, and 5 Veterans Administrative Medical Center, Houston, Texas 77030
}

During brain development, neuronal activity can transform neurons characterized by widely ranging axonal projections to ones with more restricted patterns of synaptic connectivity. Previous studies have shown that an exuberant outgrowth of local recurrent excitatory axons occurs in hippocampal area CA3 during postnatal weeks 2 and 3 . Axons are remodeled with maturation, and nearly half of the branches are eliminated. Postnatal weeks 2 and 3 also coincide with a "critical" period of development, when CA3 networks have a marked propensity to generate electrographic seizures. In an attempt to prevent axonal remodeling, local circuit activity was blocked unilaterally in dorsal hippocampus by continuous infusion of tetrodotoxin (TTX). Field potential recordings from behaving animals were dramatically altered when TTX infusion was initiated at the beginning of the critical period, week 2, but not later in life. Spontaneous, synchronized spikes and electrographic seizures

Precise patterns of synaptic connections are required for the proper functioning of the CNS. The formation of neuronal networks relies on both molecular signaling and physiological activity. For instance, initial axonal pathfinding has been shown to be dependent on molecular mechanisms such as differential adhesion, chemotropism, and repulsion (Tessier- Lavigne and Goodman, 1996). Later phases of synaptic remodeling, comprised of both axonal pruning and the expansion of selected rudimentary arbors, are thought to be dependent on neural activity (Goodman and Shatz, 1993; Katz and Shatz, 1996). In the developing cortex, visual experience is required for neural circuitry development. Monocular deprivation in kittens during a critical period of development has been shown to cause most visual cortical neurons to become unresponsive to the deprived eye and respond to the nondeprived eye (Weisel and Hubel, 1963). When activity is blocked binocularly, the formation of ocular dominance columns is prevented (Stryker and Harris, 1986). An interruption in normal axonal development is thought to underlie these physiological effects (Antonini and Stryker, 1993).

In contrast to these studies in the visual cortex, other studies have shown that blockade of thalamocortical activity does not

Received Nov. 8, 1999; revised Jan. 28, 2000; accepted Feb. 8, 2000.

This work was supported by National Institutes of Health Grants NS18309 and NS37171 and Mental Retardation Research Center Grant HD24064. We thank Ms. Bobby Antalffy for assistance with histochemical staining, Dr. Jeffrey Noebels for his guidance in the 2DG experiments, and Drs. Astrid Nehlig and Minghui Jiang for advice and helpful discussion.

Correspondence should be addressed to Dr. John W. Swann, The Cain Foundation Laboratories, 6621 Fannin, MC 3-6365, Houston, TX 77030. E-mail: jswann@bcm.tmc.edu.

Copyright (c) 2000 Society for Neuroscience $\quad 0270-6474 / 00 / 202904-13 \$ 15.00 / 0$ with behavioral accompaniments were observed after 4 weeks of TTX infusion and persisted into adulthood. When recordings were made during TTX infusion, synchronized spiking was recorded in ventral hippocampus as early as 2 weeks after infusate introduction. At this same time, extracellular field recordings from in vitro slices demonstrated spontaneous network-driven "mini-bursts" arising from ventral hippocampal slices. These were abolished by glutamate receptor antagonists. Whole-cell recordings from CA3 neurons revealed bursts of excitatory synaptic potentials coincident with the network bursts recorded extracellularly. Thus, local assemblies of mutually excitatory CA3 pyramidal cells are hyperexcitable in these rats. Whether alterations in developmental axonal remodeling mediate these effects awaits further studies.

Key words: hippocampus; epilepsy; TTX; axons; EEG; pyramidal cells

prevent the establishment of somatotopic maps (Chiaia et al., 1992, 1994). Thus, the applicability of lessons learned from the visual system to other cortical areas is uncertain. In hippocampus, local circuit axonal arbors in the rat have been described from anatomical studies of biocytin-filled CA3 hippocampal pyramidal cells (Ishizuka et al., 1990; Li et al., 1994). Results show that axons of adult pyramidal cells ramify extensively in stratum radiatum and stratum oriens of area CA3. These axon arbors mediate synaptic excitation of nearby CA3 pyramidal cells and are thought to be the anatomical substrates for the synchronized network discharging that underlies epileptiform events (Johnston and Brown, 1981; Miles and Wong, 1983, 1987; Swann et al., 1993; Smith et al., 1995).

During the first postnatal week, few recurrent axon collaterals emanate from CA3 pyramidal cells. However, by the second postnatal week an exuberant and intricate outgrowth of local recurrent collaterals has occurred. By week 10, the final pattern of adult connectivity is achieved when $50 \%$ of these axons are pruned (Gomez-Di Cesare et al., 1997). During the second and third postnatal weeks, when axonal arbors are so elaborate, the CA3 subfield has been shown to have a marked capacity to generate electrographic seizures (Swann and Brady, 1984). This has been referred to as the "critical period of CA3 network hyperexcitability" (Swann, 1995).

The ultimate goal of our studies is to determine the role neuronal activity plays in axonal development in hippocampus. In experiments reported here, local circuit activity was blocked by chronic unilateral infusion of TTX into the hippocampus. We hypothesized that exuberant recurrent axonal arbors present in early life might fail to remodel during development in TTX- 


\begin{tabular}{|c|c|c|c|c|c|c|}
\hline Experiment & $\begin{array}{l}\text { Control number } \\
\text { of rats }\end{array}$ & $\begin{array}{l}\text { Experimental } \\
\text { number of rats }\end{array}$ & $\begin{array}{l}\text { Age when infu- } \\
\text { sion began }^{a}\end{array}$ & $\begin{array}{l}\text { Duration of } \\
\text { infusion (days) }\end{array}$ & $\begin{array}{l}\text { Age when infu- } \\
\text { sion stopped }\end{array}$ & $\begin{array}{l}\text { Age when results } \\
\text { were obtained }{ }^{a}\end{array}$ \\
\hline 2-Deoxyglucose studies & 5 & 5 & 12 & 14 & 26 & 26 \\
\hline Cresyl violet studies & 5 & 5 & 12 & 28 & 40 & 40 \\
\hline \multicolumn{7}{|l|}{ In vivo $\mathrm{EEG}$ studies } \\
\hline $\begin{array}{l}\text { Recovery of neuronal activity af- } \\
\text { ter activity blockade }\end{array}$ & 6 & 15 & $12-17$ & 28 & $40-45$ & $40-54$ \\
\hline \multirow{3}{*}{$\begin{array}{l}\text { Age dependence of effects of ac } \\
\text { tivity blockade }{ }^{b}\end{array}$} & 6 & 11 & $10-12$ & 28 & $38-40$ & $38-52$ \\
\hline & 6 & 10 & $13-17$ & 28 & $41-45$ & $41-57$ \\
\hline & 2 & 6 & $45-50$ & 28 & $73-78$ & 73-90 \\
\hline Follow-up at $6-8$ months of age & 2 & 7 & $10-12$ & 28 & $38-40$ & $6-8$ months \\
\hline $\begin{array}{l}\text { Interictal spikes in dorsal vs ven- } \\
\text { tral hippocampus }\end{array}$ & 5 & 5 & $10-12$ & 28 & $38-40$ & $26-40$ \\
\hline \multicolumn{6}{|l|}{ In vitro slice studies } & $6-12$ months \\
\hline $\begin{array}{l}\text { Recordings of remote focus in } \\
\text { vitro }\end{array}$ & 3 & 5 & $10-12$ & $14-21$ & $24-33$ & $24-33$ \\
\hline $\begin{array}{l}\text { Recordings of epileptiform bursts } \\
2 \text { weeks after TTX with- } \\
\text { drawal }\end{array}$ & 2 & 3 & $10-12$ & 28 & $38-40$ & $52-54$ \\
\hline \multicolumn{7}{|l|}{ Blockade of minibursts by: } \\
\hline KYN & & 3 & $10-12$ & $14-21$ & $24-33$ & $24-33$ \\
\hline CNQX & & 3 & $10-12$ & $14-21$ & $24-33$ & $24-33$ \\
\hline Whole-cell recordings & 3 & 7 & $10-12$ & $14-24$ & $24-33$ & $24-33$ \\
\hline
\end{tabular}

${ }^{a}$ Age in postnatal days.

${ }^{b}$ Some animals in this study were also included in recovery of neuronal activity data.

inf used rats and instead remain in an immature state of excessive connectivity, thereby resulting in network hyperexcitability in adulthood.

Some of the results presented here have appeared in abstract form (Galvan et al., 1998).

\section{MATERIALS AND METHODS}

Surgery. Ninety-six Wistar rats (Harlan Sprague Dawley, Indianapolis, IN) 10 - to $12(n=78)$-, 13 - to $17(n=10)$-, or 45- to $50(n=8)$-d-old were deeply anesthetized with an intraperitoneal injection of ketamine/ xylazine (33 mg ketamine/ $\mathrm{kg}$ and $1.5 \mathrm{mg}$ xylazine $/ \mathrm{kg}$ ) and placed in a stereotaxic apparatus. The surgical procedures and use of TTX were approved by an Animal Protocol Review Committee, the Infectious Agent and Hazardous Chemical Subcommittee, and the Animal Biosafety Subcommittee of Baylor College of Medicine. All procedures were in keeping with guidelines established by the National Institutes of Health. A continuous blockade of hippocampal neuronal activity was produced by using a 28 gauge stainless steel cannula connected by polyvinyl chloride tubing to an osmotic minipump (Alzet model 2004; Alza, Palo Alto, CA), which contained $10 \mu \mathrm{M}$ TTX dissolved in an artificial CSF (ACSF (in mM): $150 \mathrm{Na}^{+}, 3.0 \mathrm{~K}^{+}, 1.4 \mathrm{Ca}^{2+}, 0.8 \mathrm{Mg}^{2+}, 1.0$ $\mathrm{PO}_{4}$, and $155 \mathrm{Cl}$ ). All control animals received ACSF vehicle alone. According to manufacturer standards, these osmotic minipumps infuse solutions at $0.25 \mu \mathrm{l} / \mathrm{hr}$ for $28 \mathrm{~d}$. To implant a cannula, a midline incision was made in the scalp to expose the skull. After stereotaxic determination of the mediolateral and rostrocaudal coordinates of the right dorsal hippocampus (posterior, $2.2 \mathrm{~mm}$; lateral, $2.0 \mathrm{~mm}$ from bregma), a small hole was formed using a high-speed dental drill.

A cannula was then implanted ( $3.2 \mathrm{~mm}$ below the surface) and adhered to the skull with dental cement followed by Superglue. After securing the cannula, the connected osmotic minipump was inserted into a preformed subcutaneous pocket along the back. The wound was then sutured over the cannula. Finally, rats were returned to their home cage for postoperative recovery. A variety of in vivo and in vitro experiments were conducted using these animals. A summary of the experiments, time of cannula implantation and explantation, and ages when data were collected are given in Table 1.

$\left[{ }^{14} \mathrm{C}\right]$ 2-deoxy-D-glucose experiments. The $\left[{ }^{14} \mathrm{C}\right]$ 2-deoxy-D-glucose
(2DG) technique for detecting cerebral glucose consumption associated with neuronal activity was used to map brain regions affected by TTX infusion (Sokoloff et al., 1974). On postnatal day 26, five TTX-infused and five saline-infused animals were injected intraperitoneally with 20 $\mu \mathrm{Ci} / 100 \mathrm{gm}$ body weight of $\left[{ }^{14} \mathrm{C}\right]$ deoxyglucose (New England Nuclear). This was 2 weeks after initiating TTX or ACSF infusion on day 12 . Forty-five minutes after 2DG injection, the animals were anesthetized with ketamine/xylazine (33 mg ketamine/ $\mathrm{kg}$ and $1.5 \mathrm{mg}$ xylazine $/ \mathrm{kg}$ ), and their brains removed and frozen on dry ice. A cryostat was used to cut $30-\mu \mathrm{m}$-thick coronal sections. The sections were thaw-mounted on coverslips, dried on a hotplate, and exposed on x-ray film (Biomax MR; Eastman Kodak, Rochester, NY) for 7-10 d. Autoradiograms of representative sections from TTX and ACSF-infused rats were scanned (Umax Astra 1200S) into a personal computer and analyzed using the NIH Image program.

Histology. Cresyl violet staining techniques were used to determine proper cannula placement and possible hippocampal damage created by implantation. On postnatal day 40, five TTX-infused and five salineinf used animals were initially perfused with $\mathrm{PBS}$, pH $7.4\left(38^{\circ} \mathrm{C}\right)$ followed immediately by $4 \%$ paraformaldehyde that was dissolved in $0.1 \mathrm{M}$ PBS, $\mathrm{pH} 7.4\left(4^{\circ} \mathrm{C}\right)$ that contained 5\% sucrose. The brains were fixed overnight and cryoprotected with $30 \%$ sucrose before sectioning with a freezing microtome. Fifty micrometer serial sections were cut and stained with cresyl violet acetate. In addition, brains of three TTX-infused animals were removed on postnatal day 26 and stored in $10 \%$ neutral buffer formalin for $24 \mathrm{hr}$. Brains were dehydrated using increasing concentrations of ethanol followed by two incubations in chloroform. Brains were then embedded in paraffin, and $10-\mu \mathrm{m}$-thick sections were cut and subsequently stained with cresyl violet acetate.

EEG electrode implantation. Eight EEG recording electrodes were implanted in 32 TTX-infused animals and 13 ACSF-inf used animals. In the first series of experiments, 15 TTX-infused and six control animals were used to verify that TTX infusion blocked neuronal activity and to determine the time required for background EEG activity to recover after TTX withdrawal. To accomplish this, two silver electrodes (exposed tips of 0.005 inch diameter, Teflon-coated silver wires; A-M Systems) were twisted together and stereotaxically implanted bilaterally in hippocampus on day 40, $28 \mathrm{~d}$ after initiating TTX or ACSF vehicle infusion. The electrodes were implanted at the infusion site immediately 
after cannula extraction. To avoid contamination from signals arising from other brain areas, differential recordings were made between the electrode pairs in each hippocampus. Surface electrodes were also placed bilaterally over somatosensory cortex, and a reference electrode was placed over the medial occipital cortex. A ground electrode was placed in the right occipital muscle group. Dental cement was used to secure the electrode wires in place and to form a protective cap around a plug to which the electrodes were connected.

In another series of experiments, five TTX-infused and five control animals were monitored within the ventral hippocampus while TTX infusion of the dorsal hippocampus was ongoing. To accomplish this, an electrode was implanted into both the dorsal and ventral hippocampus of the infused and uninfused hippocampus on day 26, $14 \mathrm{~d}$ after initiating TTX or ACSF vehicle infusion. EEG electrodes within the dorsal inf used hippocampus were implanted near the infusion site. Stereotaxic coordinates, adjusted for growth, for the left and right dorsal hippocampus from bregma were posterior $3.2 \mathrm{~mm}$, lateral $3.2 \mathrm{~mm}$, and depth of 3.8 $\mathrm{mm}$. Coordinates for the left and right ventral hippocampus taken from bregma were posterior $5.6 \mathrm{~mm}$, lateral $4.8 \mathrm{~mm}$, and depth $6.2 \mathrm{~mm}$. Surface electrodes were placed over each somatosensory cortex, and a reference electrode was placed over the occipital cortex. A similar recording montage was used in studies of rats infused beginning on days 45-50 (TTX-infused, $n=6$; ACSF-inf used, $n=2$ ) and six additional rats inf used with TTX beginning on days $10-12$.

Video EEG monitoring. A 20 channel Nihon Kohden EEG machine with an attached video camera was used to monitor each animal at least $1 \mathrm{hr}$ daily for up to $16 \mathrm{~d}$. Recordings were made at a paper speed of 30 $\mathrm{mm} / \mathrm{sec}$ and a sensitivity of $30-75 \mu \mathrm{V} / \mathrm{mm}$. A referential montage was used in which left and right cortical and hippocampal electrodes were referred to the medial occipital cortex. Because the EEG differs markedly during phases of sleep-wake cycles, analyses were always restricted to defined times in this cycle. Hippocampal theta activity was monitored during wakefulness. Interictal epileptiform discharges were analyzed during non-REM sleep.

Long-term video monitoring. An infrared surveillance camera (Sanyo) and time-lapse VCR were used to monitor seven animals, 6-8 months after TTX cannula extraction, and two control animals 8 months and 1 year after ACSF cannula extraction. Animals were recorded in their home cages for $5 \mathrm{~d}, 14 \mathrm{hr} / \mathrm{d}$.

In vitro slice experiments. Hippocampal slices were taken from 18 TTX-infused and 7 ASCF-infused rats 25 - to 60 -d-old. The rats were deeply anesthetized with methoxyflurane (Metophane), and the brain was rapidly removed and placed in ice-cold ACSF (in mM: $3.5 \mathrm{KCl}, 1.5$ $\mathrm{MgSO}_{4}, 1.5 \mathrm{CaCl}_{2}, 122.75 \mathrm{NaCl}, 10$ glucose, $1.25 \mathrm{NaH}_{2} \mathrm{PO}_{4}$, and 26 $\mathrm{NaHCO}_{3}$ ). Blind whole-cell recording experiments were performed on slices from seven TTX-infused and three ACSF-infused rats. Field potential recordings were obtained in slices from the remaining rats. To make slices, the hemispheres were separated, blocked, and secured to a vibratome platform with Superglue and submerged in oxygenated saline. Four hundred-micrometer-thick sections were cut transverse to the longitudinal axis of the hippocampus. In five rats, abnormal network activity was monitored along the septotemporal axis of the hippocampus. The hippocampus was dissected free from the rest of the brain, and 400- and 500- $\mu \mathrm{m}$-thick slices, transverse to the longitudinal axis, were cut with a tissue chopper starting anterior to the visualized infusion site in the dorsal hippocampus and successively through the ventral hippocampus.

Slices obtained by both described methods were transferred to an interface recording chamber containing $\mathrm{ACSF}$ at $32^{\circ} \mathrm{C}$. The lower surfaces of the slices were constantly perfused with oxygenated ACSF, and the upper surfaces were exposed to a humidified mixture of $95 \% \mathrm{O}_{2}$ and $5 \% \mathrm{CO}_{2}$. The tissue was maintained for $1 \mathrm{hr}$ under these conditions. Thereafter, extracellular field recordings were made with microelectrodes filled with $2 \mathrm{M} \mathrm{NaCl}(5-10 \mathrm{M} \Omega)$. Blind whole-cell recordings were made with patch electrodes (7-10 M $\Omega$ ) containing the following (in $\mathrm{mM}$ ): $120 \mathrm{~K}$ gluconate, $20 \mathrm{KCl}, 10 \mathrm{EGTA}, 10 \mathrm{HEPES}$, and $2 \mathrm{MgCl}_{2}, \mathrm{pH} 7.25$; osmolarity, 270-280 mOsm. A cell was accepted for study if it had a resting membrane potential of at least $-50 \mathrm{mV}$ and a spike amplitude of $60 \mathrm{mV}$ or greater.

In slices from six rats, KYN $(500 \mu \mathrm{M})$ or CNQX $(2 \mu \mathrm{M})$ was bathapplied. All electrophysiological data were stored on tape for later analysis. Selected signals were collected and analyzed with software developed for a personal computer. Signals were digitized at $10-40 \mathrm{kHz}$ and then plotted using the scientific software package, Origins 5.0. Results are presented as mean \pm SEM. Statistical analyses were performed with SigmaStat.

\section{RESULTS}

\section{Comparison of 2DG uptake in TTX-infused and saline-infused hippocampus}

Figure 1 compares results obtained from a TTX-inf used rat $(A)$ and a saline-infused control rat $(B)$. The image of a Nissl-stained section in panel $\mathrm{C}$ is presented for anatomical reference. TTX infusion began on day 12, and rats were killed 2 weeks later. Results in panel A show TTX inf usion markedly suppressed 2DG uptake at the infusion site (arrow). Glucose metabolism in the infused hippocampus is comparable to that of white matter. The contralateral hippocampus has much higher and likely normal 2DG uptake. The autoradiograms from the saline-infused rat in panel B show that the infused hippocampus was comparable to the contralateral hippocampus with regard to $2 \mathrm{DG}$ uptake.

To determine the area affected by TTX infusion, serial coronal sections, rostral and caudal to that in panel A, were analyzed. Panel D shows results from a section that was $1 \mathrm{~mm}$ rostral to that in panel A, whereas panel $\mathrm{E}$ was obtained $3 \mathrm{~mm}$ caudal. The edge of the cannula tract is visible in panel D where a markedly decreased 2DG uptake is observed (arrow). However, the image in panel E suggests glucose metabolism is normal in hippocampal tissue that is more remote from the infusion site. Serial coronal sections taken from five TTX-infused rats along the rostrocaudal axis, showed that the reduction in 2DG uptake was restricted to the inf used dorsal hippocampus. Decreased 2DG uptake was seen up to $2 \mathrm{~mm}$ anterior and $1 \mathrm{~mm}$ posterior to the infusion site. On average, a reduction in $2 \mathrm{DG}$ uptake was observed $2.4 \pm 0.99 \mathrm{~mm}$ (mean $\pm \mathrm{SEM}, n=5$ rats) along the longitudinal axis of the hippocampus. An image of the dorsal hippocampus from a Nisslstained section is shown in panel F. This section was taken from a rat after 2 weeks of TTX infusion. The cannula tract (arrow) is visible as it passes through the overlying cortex and the hippocampal CA1 subfield. The tip of the cannula was located in stratum radiatum. The hippocampal laminae and pyramidal cell body layer do not appear to be disrupted by the cannula or chronic infusion of TTX.

\section{Electroencephalography}

Recovery of baseline EEG

To further verify the blockade of neuronal activity and to determine the time course of recovery after cannula extraction, EEG recordings were undertaken. The amplitude of hippocampal theta rhythm was used as a measure of neuronal activity. This rhythm is an easily identifiable and stereotypic component of hippocampal EEG activity. It is seen predominantly in wakefulness and REM sleep and is reduced during slow wave sleep. The amplitude of hippocampal theta rhythms was estimated from EEG traces sampled during comparable periods of wakefulness at three separate times during daily $2 \mathrm{hr}$ recording sessions. Thirty measurements of the peak-to-peak amplitude were averaged in recordings from each animal each day. The graph in Figure $2 A$ plots the amplitude of hippocampal theta activity recorded from ACSFinfused animals $(n=6)$ beginning immediately after ACSF cannula extraction. It shows a transient relative depression of theta activity during the initial $2 \mathrm{~d}$ of recording, but activity recovered and then remained constant during the subsequent $10 \mathrm{~d}$ of recordings. The initial slight depression on days 1 and 2 may be the result of surgery. In contrast, recordings from TTX-inf used animals $(n=15)$ beginning immediately after TTX cannula extraction showed a very marked depression of hippocampal EEG activity that was restricted to the inf used hippocampus (Fig. $2 B$ ). Daily EEG recordings showed activity gradually returned to 

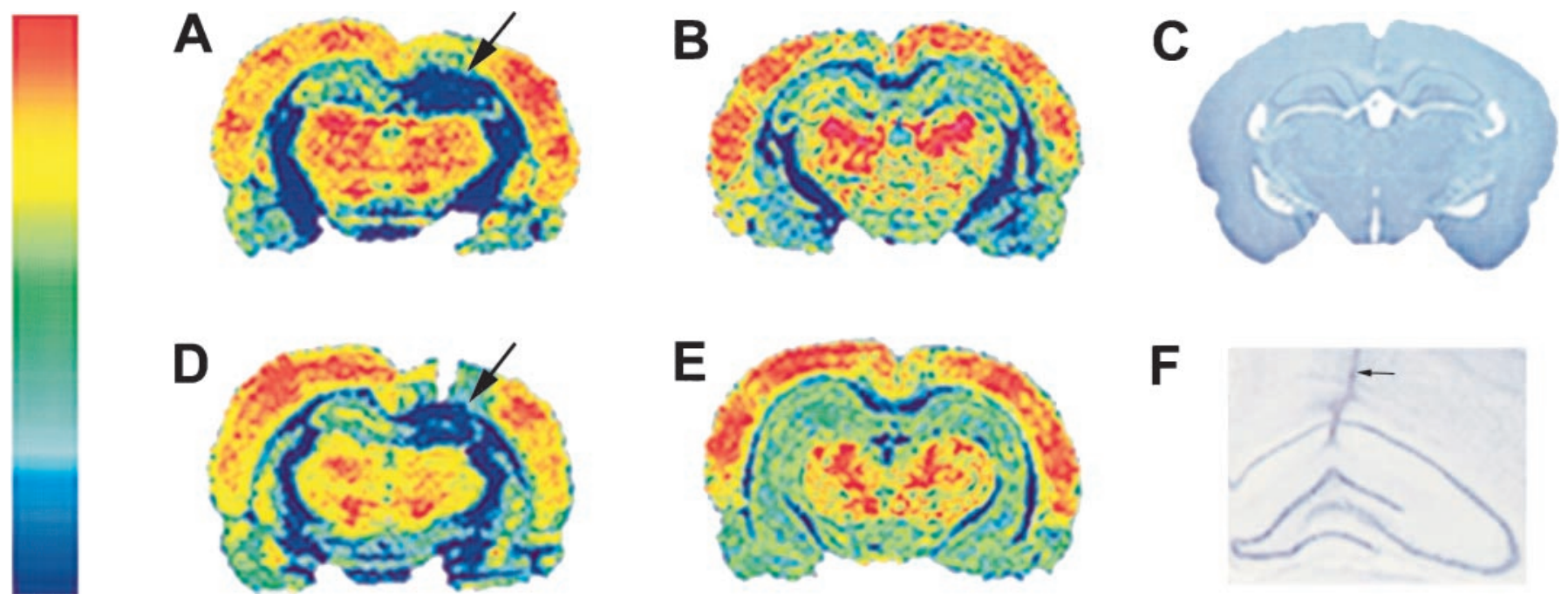

Figure 1. TTX produces a region of focal hypometabolism in infused dorsal hippocampus. Pseudocolored autoradiograms of 2DG-labeled coronal sections taken from a TTX-inf used animal and ACSF-infused animals are shown in panels $A, B, D$, and $E$. The color patterns represent gray scale values of 2DG uptake. The color scale to the left indicates blue as the lowest level of 2DG uptake, whereas red indicates the highest. $A$, A coronal section from a TTX-infused animal reveals almost complete blockade of 2DG uptake in the infused hippocampus (arrow). $B$ is a coronal section that shows normal 2DG levels in both the contralateral and ipsilateral ACSF-inf used hippocampus. $D$, A section taken more anterior to that in $A$ in the TTX-inf used animal shows a similar blockade of 2DG uptake in the infused hippocampus (arrow). In $E$, a section taken 3 mm posterior through the ventral hippocampus of a TTX-infused hippocampus shows no signs of hypometabolism and no differences in 2DG uptake between the infused ipsilateral and contralateral hippocampus. $C$ is a Nissl-stained section taken from a control animal, which provides anatomical guides for $A, B$, and $D$. $F$ is an image taken at higher magnification of a TTX infusion site. The cannula tract (arrow) is readily evident. However, no signs of neuronal loss or excessive reactive gliosis are apparent.

normal levels by the 12th day of EEG monitoring. A transient depression, similar to that seen in ACSF-infused controls can be seen in contralateral hippocampus of TTX-inf used rats. Figure $2 C$ shows representative examples of EEG traces taken on days 2, 6 , and 12 from a TTX-infused animal. Note the dramatic depression of hippocampal theta activity in the infused dorsal hippocampus (trace 2) compared to the levels of activity shown in the uninfused hippocampus (trace 1) $2 \mathrm{~d}$ after TTX cannula extraction. On day 6 of EEG monitoring, hippocampal theta activity had partially returned to levels recorded in the uninfused hippocampus. Twelve days after TTX cannula extraction, hippocampal theta activity had completely recovered.

\section{Interictal spike and seizure activity}

Unexpectedly, during the course of EEG recordings, interictal spikes were also recorded. An example of such a recording is shown in Figure $3 B$. In this instance, interictal spikes (some marked by arrows) were recorded during non-REM sleep in the left dorsal hippocampus contralateral to the site of infusion, the left and right ventral hippocampus, and left somatosensory cortex. When TTX infusion began on day 10-12, 10 of 11 (91\%) animals showed similar spontaneous interictal spike activity that could arise from the contralateral or infused hippocampus or bilaterally from neocortex as well. However, epileptiform discharging did not consist solely of interictal spikes. Eight of the 11 animals (73\%) had both electrographic and behavior seizures beginning on day 2 of EEG monitoring. Figure $3 C$ shows an electrographic seizure. These discharges were highly stereotyped from animal to animal and consisted of a brief run of high-frequency spikes. Behavioral seizures always accompanied these electrographic events. The seizures consisted of a tonic posturing of the head and upper trunk to the left or right. This was accompanied by predominantly left but on some occasions right forelimb clonus and excessive chewing. Seizures recorded within 4 weeks of TTX cannula extraction were on average $3.0 \pm 0.2 \mathrm{sec}$ in duration. EEG monitoring showed seizure frequency ranged from 0.2 to 4.7 seizures per $3 \mathrm{hr}$ recording period and averaged $1.47 \pm 0.52$ seizures every $3 \mathrm{hr}$.

To determine if seizures were unique to rats, in which blockade of hippocampal activity began on day 10-12, TTX infusion was begun later in development. First, TTX infusion was initiated between days 13 and 17 in 10 rats. Interictal spike activity was seen in only three $(30 \%)$ of these animals. None of these animals had electrographic or behavioral seizures. Six age-matched control animals showed no abnormal interictal or seizure activity.

EEG recordings were also obtained from six animals in which TTX inf usion began on postnatal days 45-50 and continued for 4 weeks. Two age-matched control animals received ACSF for the same period. No interictal or ictal activity was recorded from either the animals infused with TTX or the control animals infused with ACSF. A comparison of the frequency of interictal and seizure activity observed between the three age groups showed the proportion of animals displaying abnormal activity in the day 10-12 infusion group (interictal spikes in 10 of 11 rats, ictal discharges in 8 of 11 rats) differed significantly from that of day 13-17 (interictal spikes in 3 of 10 rats, ictal discharges in 0 of 10 rats; $p<0.05, \chi^{2}$ analysis) and days $45-50$ (interictal spikes in 0 of 6 rats, ictal discharges in 0 of 6 rats; $p<0.01$ ).

\section{A chronic focal epilepsy follows TTX cannula extraction}

Casual observance of rats 2 and 3 months after TTX cannula extraction (when TTX infusion began on day 10-12) indicated that they were continuing to have seizures. To document this, seven TTX-inf used animals that had been found to have electrographic and behavioral seizures soon after TTX cannula extraction (Fig. 3C) were reimplanted for EEG monitoring 6-8 months after the initial EEG recordings. EEG recordings from each 

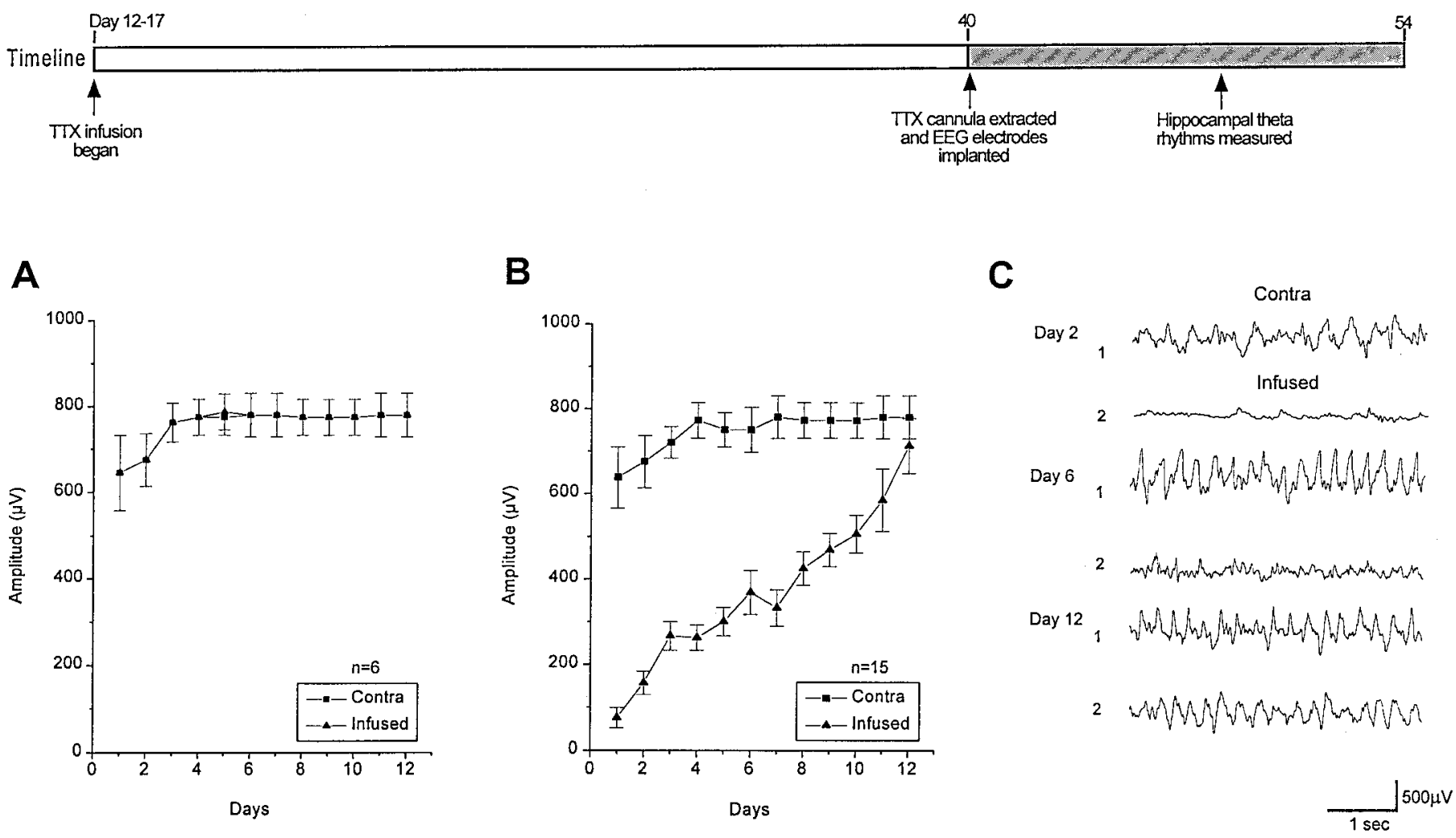

Figure 2. Comparison of hippocampal theta activity recorded from TTX- and ACSF-infused animals after 4 weeks of infusion starting on days $10-12$. The timeline summarizes experimental design. In $A$, the amplitudes of the hippocampal theta rhythms are plotted that were recorded from the ACSF-infused and contralateral hippocampus. $B$ compares the amplitude of theta rhythms recorded from TTX-inf used and contralateral hippocampus. $C$ compares representative EEG traces of TTX-infused hippocampal theta activity (traces 2 ) on days 2,6 , and 12 to that recorded simultaneously in contralateral hippocampus (traces 1).

TTX-infused animal revealed prolonged electrographic seizures. Representative portions of a $77 \mathrm{sec}$ electrographic seizure recorded 8 months after TTX cannula extraction are shown in Figure 4. An attenuation of background activity was seen at the onset of the seizure. This was associated with the appearance of high-frequency spikes in the right hippocampus and rhythmic theta activity in the left hippocampus. Thereafter, more synchronized and generalized discharges were observed until the termination of the seizure (Fig. $4 B, C$ ). In the seven rats, seizures were on average $89 \pm 10 \mathrm{sec}$ in duration. The electrographic seizures, like that shown in Figure 4, had consistent behavioral accompaniments. As observed earlier in life, seizures began with a tonic posturing of the head and the upper trunk and forelimb clonus. As the seizure progressed, rats would rear on their hind legs and display bilateral forelimb clonus, chewing, and rapid eye blinking. They would then fall to one side.

The animals were then video monitored for $14 \mathrm{hr} / \mathrm{d}$ on five separate days. All seven TTX-infused animals had frequent seizures, which averaged $4.48 \pm 0.56$ seizures/14 hr.

\section{Interictal spikes arise from ventral hippocampus during TTX infusion of dorsal hippocampus}

Because electrographic and behavioral seizures were observed immediately after TTX cannula extraction while activity in the inf used dorsal hippocampus was still depressed (Fig. 2), we hypothesized that seizures might be occurring at a time when dorsal hippocampal activity was blocked by TTX infusion. To address this question, we monitored EEG activity bilaterally in the dorsal and ventral regions of the hippocampus while inf usion of the right dorsal hippocampus was ongoing. EEG electrodes were implanted in five TTX-infused and five ACSF-infused animals without removing the osmotic pump. On day 22 of TTX infusion (postnatal day 34), all five TTX-infused animals had interictal discharging recorded in ipsilateral ventral hippocampus, indicating the presence of hyperexcitable hippocampal networks in tissue remote from the inactive TTX-infused dorsal hippocampus. We refer to this area as a "remote focus." Figure $5 A$ shows recordings from one of these rats. Interictal spikes denoted by the arrows are seen in recordings from right ventral hippocampus (RVH-C).

In Figure $5 B$, dots denote the occurrence of interictal spikes recorded by six electrodes during a 15 min recording session on day 34 . Note the vast majority of spikes $(n=15)$ arising from the RVH-C. Only two spikes were recorded at other sites. Thus, this chronic epilepsy appears to arise from the infused hippocampus, but at a site remote from the infusion site. Recordings obtained just a few days later were quite different. Figure $5 C$ shows the occurrence of interictal spikes in the same animal as in panel B but on day 27 of TTX infusion (postnatal day 39). Whereas relatively few spikes were observed in dorsal hippocampus, leads in ventral hippocampus and cortex show multifocal spikes. Thus, the epileptic condition appears to evolve from a focal to a multifocal epilepsy. This later finding is consistent with our observation that multiple independent foci are present in epileptic rats after extraction of the TTX infusion cannula (Fig. 3B). With continued maturation, electrographic seizures were recorded. These seizures often arose from the ventral hippocampus. 


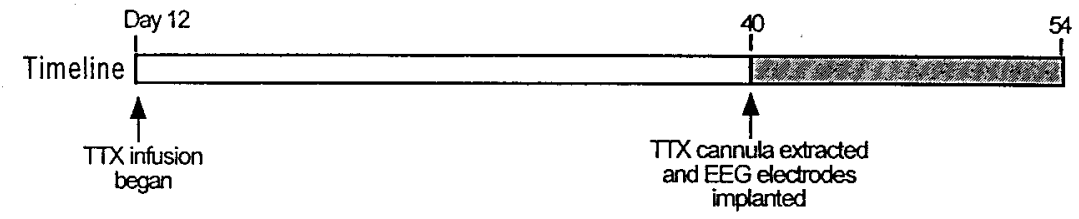

A
LDH-C

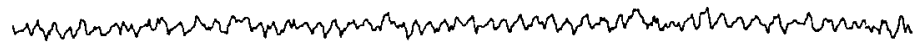
$\mathrm{RDH}-\mathrm{C}$

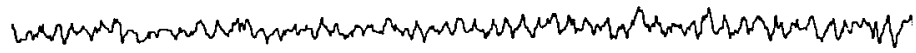
LVH-C

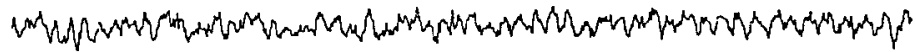
RVH-C

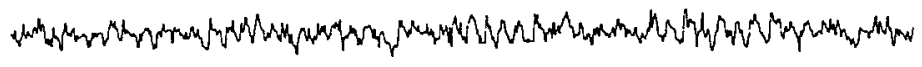
LCX-C

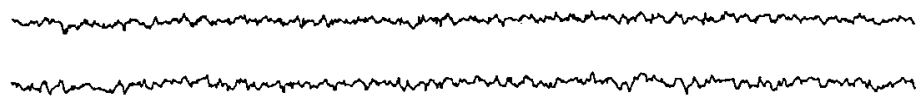

B

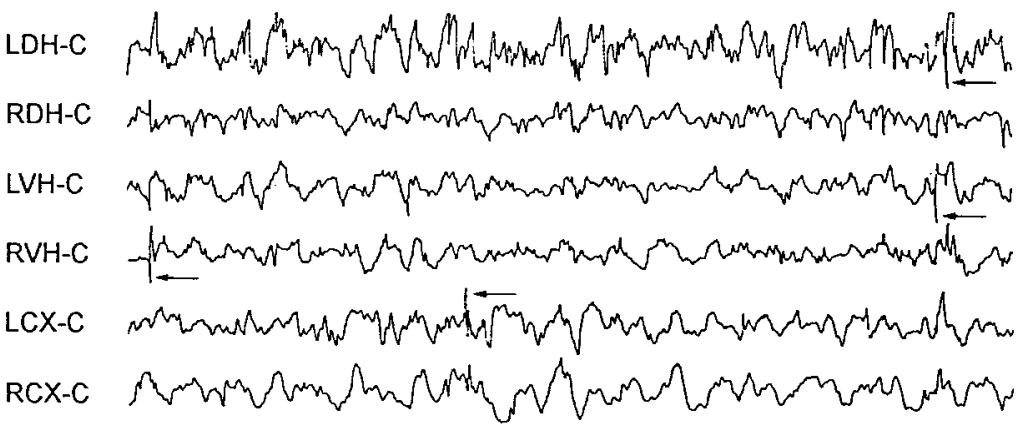

Figure 3. EEG recordings from ACSF- and TTXinfused animals $4 \mathrm{~d}$ after cannula extraction. Timeline depicts experimental design. Surface electrodes were placed over the left cortex $(L C)$ and right cortex $(R C)$, and depth electrodes were placed in the left dorsal hippocampus $(L D H)$, right dorsal hippocampus $(R D H)$, left ventral hippocampus $(L V H)$, and the right ventral hippocampus $(R V H)$. An electrode placed over the occipital cortex midline $(C)$ served as a reference electrode. TTX was inf used into the right dorsal hippocampus. $A$, Representative EEG traces of normal hippocampal activity obtained from an ACSF-infused animal $4 \mathrm{~d}$ after cannula extraction. $B$ shows representative EEG traces from a TTX-inf used animal showing multifocal interictal spikes during non-REM sleep. $A r$ rows denote representative spikes. $C$ is a representative trace showing a brief electrographic seizure recorded from a TTX-infused animal during non-REM sleep. Arrows denote the beginning and end of the seizure.

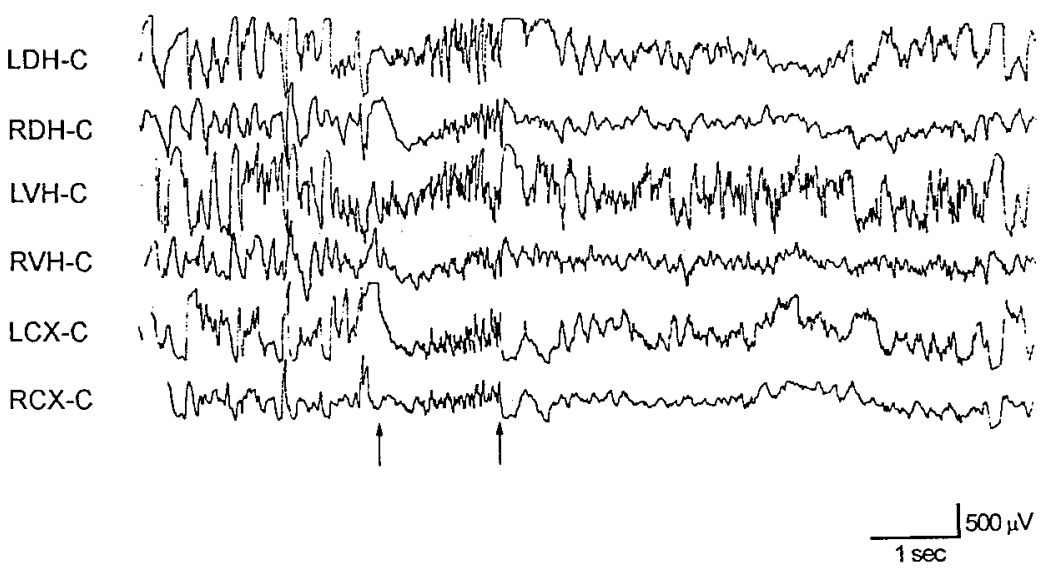

\section{A "remote focus": expression in vitro}

Next, in vitro slice experiments were conducted to characterize the cellular origin of the discharges recorded in vivo. The first experiments set out to determine if a remote focus could be demonstrated in vitro. Serial slices were taken from dorsal to ventral hippocampus in five animals during the third week of TTX infusion. Spontaneous network discharges were recorded in all experiments and predominantly in ventral slices. Figure $6 A$, trace 1, shows extracellular field recordings that demonstrate the lack of synchronized activity in the CA3 pyramidal layer of ACSF-infused animal. Figure $6 A$, trace 2, shows spontaneous synchronized network discharges recorded from the CA3 cell

body layer of a TTX-infused animal. The event marked by an asterisk is shown in the inset at a faster time base. The graph in Figure $6 B$ demonstrates that spontaneous network discharges were observed predominantly in ventral hippocampal slices. Plotted is the percentage of slices, taken at varying distances along the dorsoventral axis of the hippocampus, that displayed network discharging. The most dorsal (TTX-infused) slices had no activity, whereas nearly all slices from ventral hippocampus displayed bursting. These findings support results from EEG recordings and suggest an epileptic focus exists in the ventral portion of the inf used hippocampus during TTX infusion.

The field potential discharges shown in Figure 6 are quite 


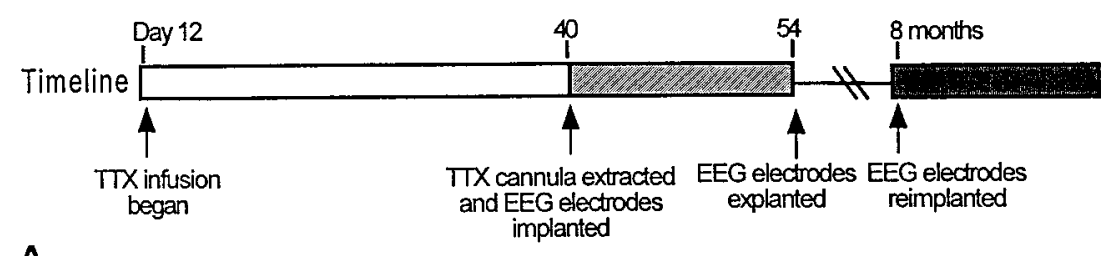

A

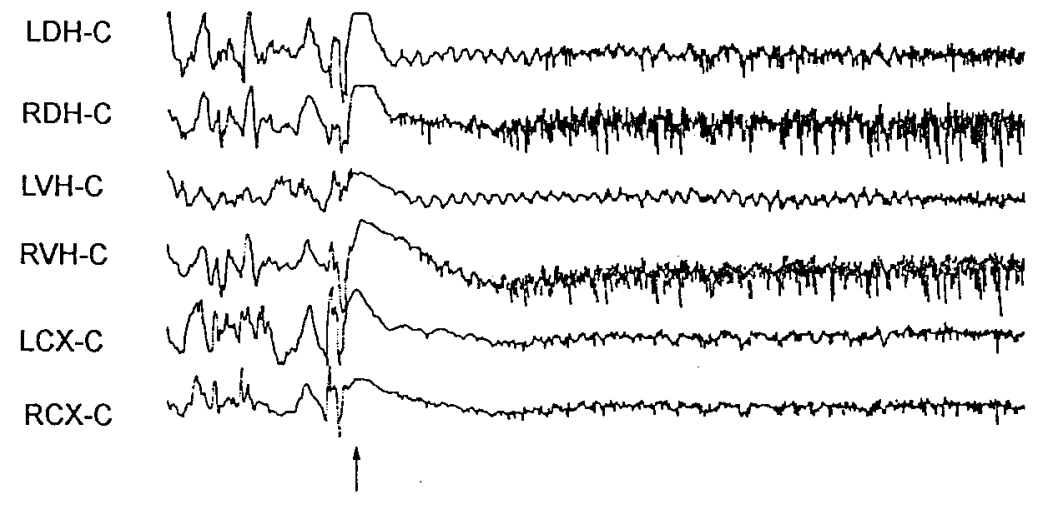

B

LDH-C

RDH-C

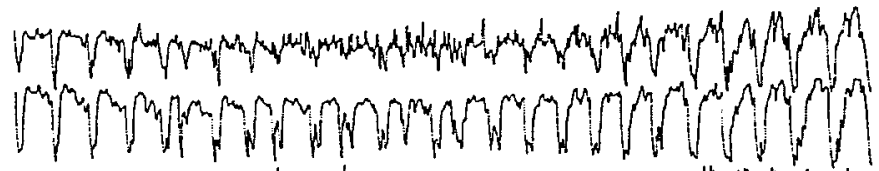

LVH-C

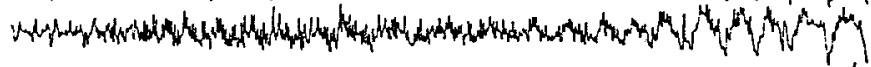

RVH-C

LCX-C

RCX-C

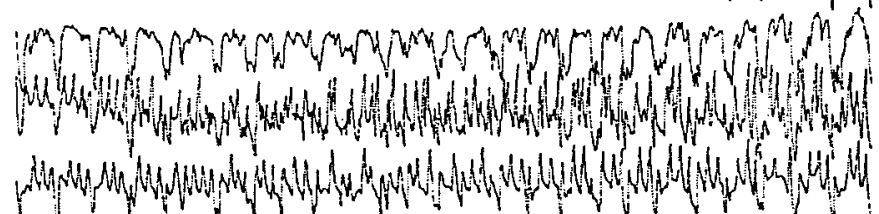

C

LDH-C

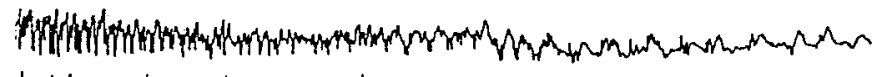

$\mathrm{RDH}-\mathrm{C}$

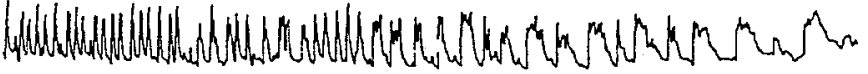

LVH-C

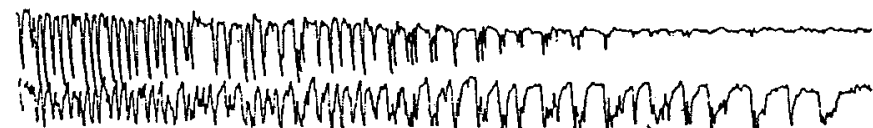

RVH-C

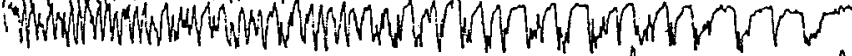

LCX-C

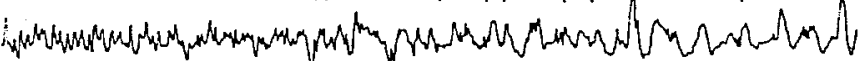

$\operatorname{RCX}-\mathrm{C}$

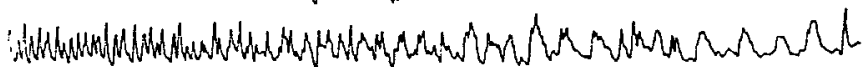

Figure 4. An electrographic seizure recorded 8 months after TTX cannula extraction. Surface electrodes were placed over the left cortex $(L C)$ and right cortex $(R C)$, and depth electrodes were placed in the left dorsal hippocampus $(L D H)$, right dorsal hippocampus $(R D H)$, left ventral hippocampus $(L V H)$, and the right ventral hippocampus $(R V H)$. An electrode placed over the midline occipital cortex $(C)$ served as a reference electrode. A referential montage was used. This seizure began with a run of high-frequency spikes (top panel, arrow) in right hippocampus and rhythmic theta activity in left hippocampus. Timeline illustrates experimental design. This seizure was $77 \mathrm{sec}$ in duration. Segments of traces at the beginning $(A)$, middle $(B)$, and end $(C)$ of the seizure are shown. different from the epileptiform burst recorded when in vitro slices are exposed to convulsant drugs such as the $\mathrm{GABA}_{\mathrm{A}}$ receptor antagonists such as picrotoxin $(20 \mu \mathrm{M})$ or penicillin $(1.7 \mathrm{mM})$ (Swann et al., 1986). When extracellular recordings are made from the CA3 cell body layer, epileptiform bursts consist of a large $(2-10 \mathrm{mV})$ positive-going field potential that are 100-200 msec in duration. Multiple population spikes are recorded riding the envelope of this potential. Individual pyramidal cells undergo an intense "depolarization shift" concurrent with this field potential. The events recorded in TTX-infused rats are lower in voltage, shorter in duration, and occur more frequently. We have referred to them as "mini-bursts". The underlying assumption has been that they are produced by the synchronized discharging of fewer pyramidal cells than the epileptiform bursts. If this hypothesis is true, then slices taken from older chronically epileptic rats that have more prolonged seizures (Fig. 4) would be expected to display full blown network bursts and not the minibursts shown in Figure 6. Results in Figure 7 support this hypothesis. Panel A compares in vitro slice recordings from slices made on postnatal day 26 (trace 1) and 54 (trace 2). TTX inf usion began in both rats on day 12 (Fig. 7, timelines). TTX was still being infused on day 26 , but the cannula was extracted on day 40,2 weeks before 

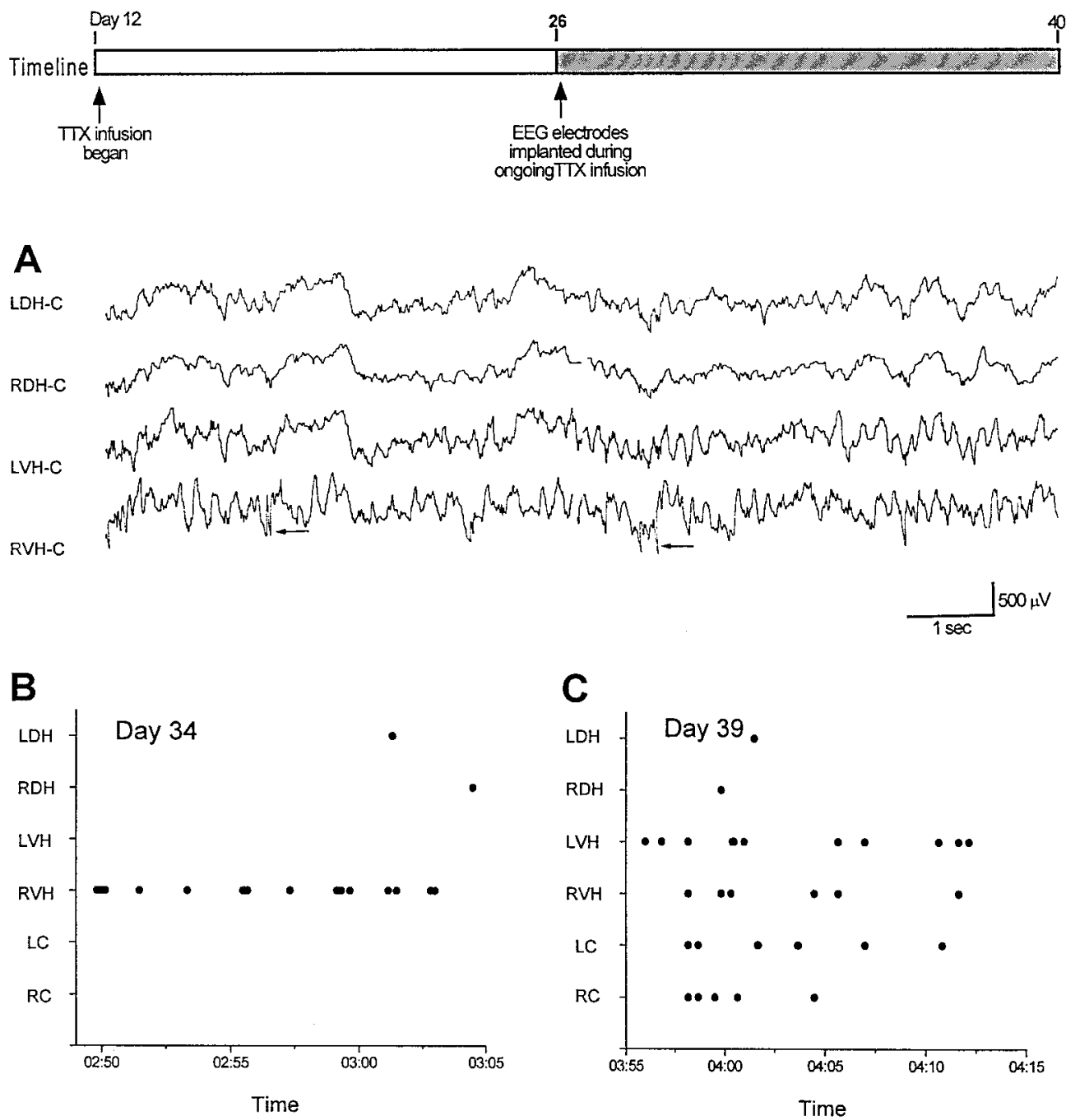

Figure 5. Interictal spikes recorded during TTX infusion illustrate a hyperexcitable surround in ventral hippocampus. Timeline depicts experimental design. $A$ shows interictal spiking (arrows) arising from the right ventral hippocampus $(R V H)$ on postnatal day $34(22 \mathrm{~d}$ of TTX infusion). $B$ shows the time of occurrence of interictal spikes recorded by six electrodes during $15 \mathrm{~min}$ of recording. A single focus predominates at this time. In $C$, multiple independent foci were recorded $5 \mathrm{~d}$ later in the same animal $(C)$.

A

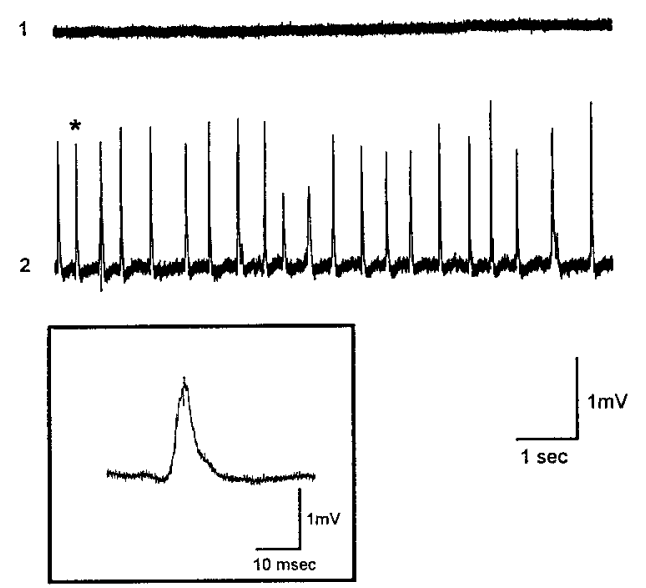

B

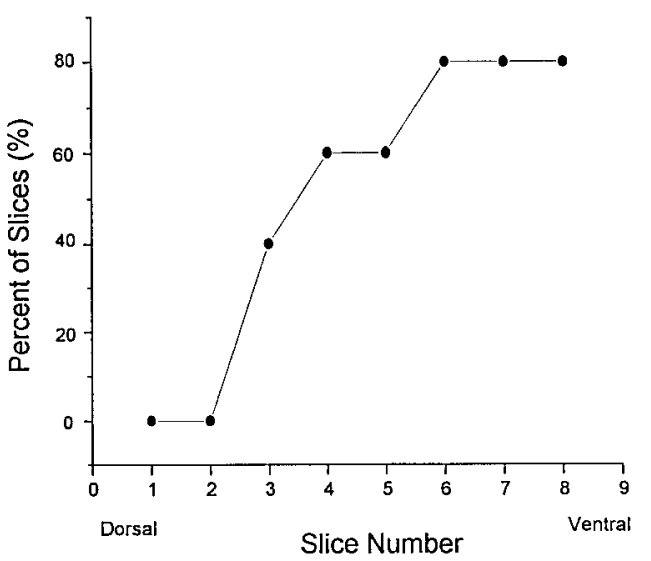

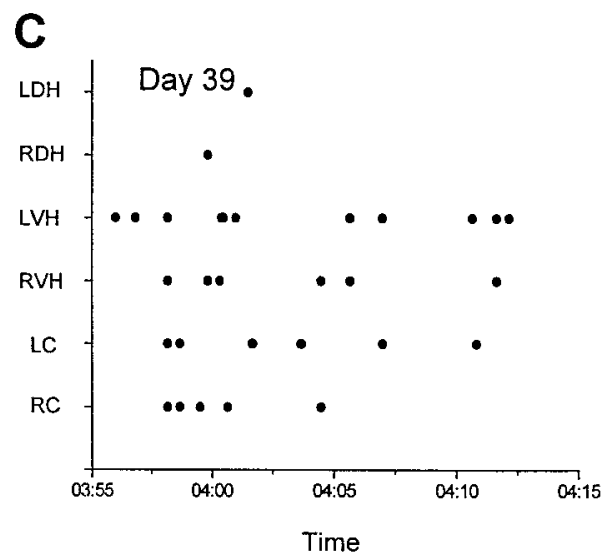

Figure 6. Spontaneous network minibursts recorded in hippocampal slices taken immediately after TTX cannula extraction. In this experiment, TTX infusion began on postnatal day 12 , and slices were taken on postnatal day 26 as TTX was infused. $A$, Extracellular recordings from $\mathrm{ACSF}$ and TTX-inf used animals. Trace 1, A slow time base extracellular field recording that demonstrates the lack of spontaneous network bursting in the CA 3 cell body layer of an ACSF-infused animal. Trace 2, Spontaneous synchronized network minibursts from the CA3 cell body layer of a TTX-infused animal. A selected event (asterisk) in the slow timebased recordings in trace 2 is expanded in time in the inset. $B$, Plotted are the percentage of slices from dorsal through ventral hippocampus that showed spontaneous network minibursts. Slices were taken from the TTX-inf used hippocampus of five rats. recordings in trace 2 were made. As can be seen, typical epileptiform network bursts were recorded in the older rat whereas small minibursts were recorded in the younger rat. Events marked by an asterisk are shown in panel B at a faster time base.
If the mini-bursts recorded in the younger TTX-infused rats were produced by synchronized discharging of local assemblies of mutually excitatory CA3 pyramidal cells, then they should be suppressed by excitatory amino acid receptor antagonists. To test 


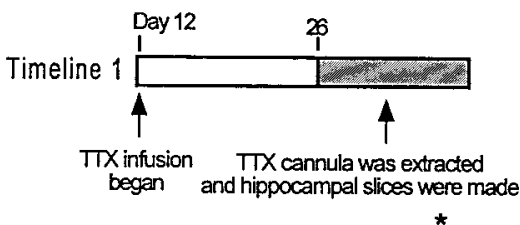

*

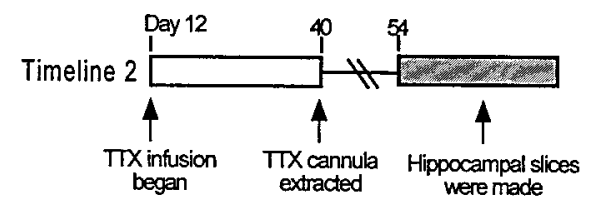

A

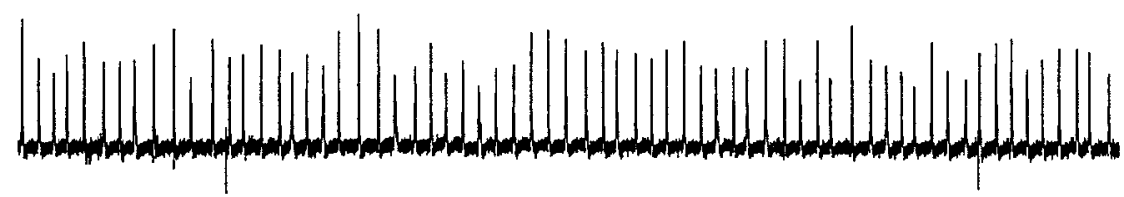

1

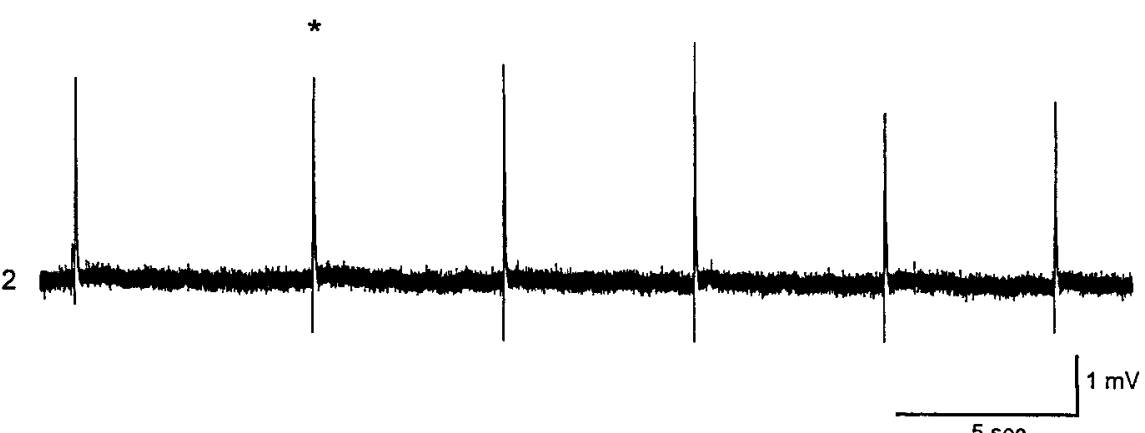

B

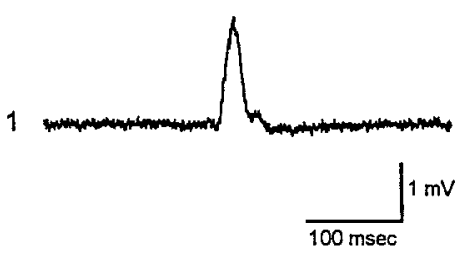

this possibility, $500 \mu \mathrm{M}$ kynurenic acid (KYN) was bath-applied during experiments in which minibursts were observed in three TTX-inf used animals (Fig. 8). All recordings were made between postnatal days 24 and 33, 2-3 weeks after initial TTX infusion. KYN completely abolished the spontaneous network discharges in four slices from these animals. The KYN effects were readily reversed after wash. In addition to $\mathrm{KYN}$, we also studied the effects of CNQX on spontaneous network minibursts. Spontaneous network discharges recorded in a total of six slices from three separate TTX-infused animals were blocked during bath application of $2 \mu \mathrm{M}$ CNQX. Taken together, the effects of both KYN and CNQX suggest that the spontaneous network bursts are mediated by excitatory amino acid synaptic transmission and likely recurrent excitatory synaptic transmission.

\section{Spontaneous network discharges coincide with barrages of synaptic potentials and CA3 pyramidal cell firing}

To determine the cellular origins of the extracellularly recorded network discharges, whole-cell recordings were obtained from CA3 pyramidal cells on postnatal days 24-33. Recordings were obtained from 10 pyramidal cells in slices from seven TTXinf used hippocampi. Coincident with minibursts recorded extracellularly in the CA3 pyramidal cell body layer, all cells received bursts of synaptic potentials that often evoked action potentials. Results from one experiment are shown in Figure 9. Traces 1 display continuous whole cell recordings from TTX-inf used hippocampal slices, whereas traces 2 are simultaneous extracellular field recordings made nearby in the CA3 cell body layer. Record-
Figure 7. Spontaneous network discharges recorded in vitro evolve from minibursts to intense network discharges. Timelines 1 and 2 depict experimental design for traces 1 and 2 in $A$ and $B$. $A$, Trace 1 shows a slow time base record of extracellular field recordings from a slice taken from an animal immediately after 2 weeks of TTX infusion. Trace 2 is a recording from a slice taken from an animal 2 weeks after 4 weeks of TTX infusion. Events denoted by asterisks in $A$ are shown in $B$ at a faster time base.
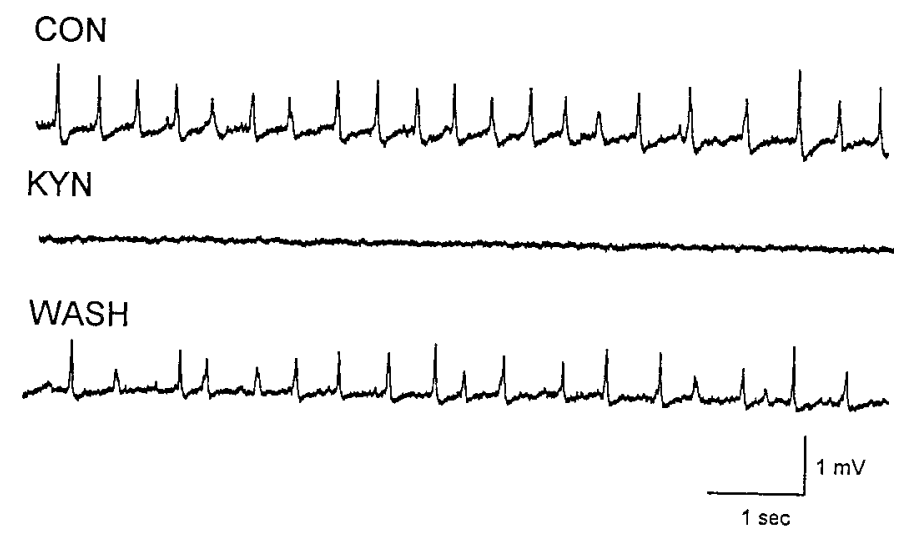

Figure 8. Kynurenic acid $(K Y N)$ blocks spontaneous network minibursts. Top, Spontaneous minibursts were recorded under control $(C O N)$ conditions in a slice taken from ventral hippocampus during TTX infusion of dorsal hippocampus. Middle, Bath application of KYN (500 $\mu \mathrm{M})$ to hippocampal slices blocked the minibursts. Bottom, Spontaneous minibursts returned after washout of KYN.

ings show that minibursts were coincident with large intracellular depolarizations that often elicited action potentials. Events outlined in boxes in the middle and lower sets of traces in Fig. $9 A$ are shown below in Fig. $9 B a-B d$ at a faster time base.

Because $E_{\mathrm{Cl}}$ was slightly depolarizing in our whole-cell recordings $\left(E_{\mathrm{Cl}}=-48 \mathrm{mV}\right)$, neurons were routinely depolarized by intracellular current injections to demonstrate that synaptic event 


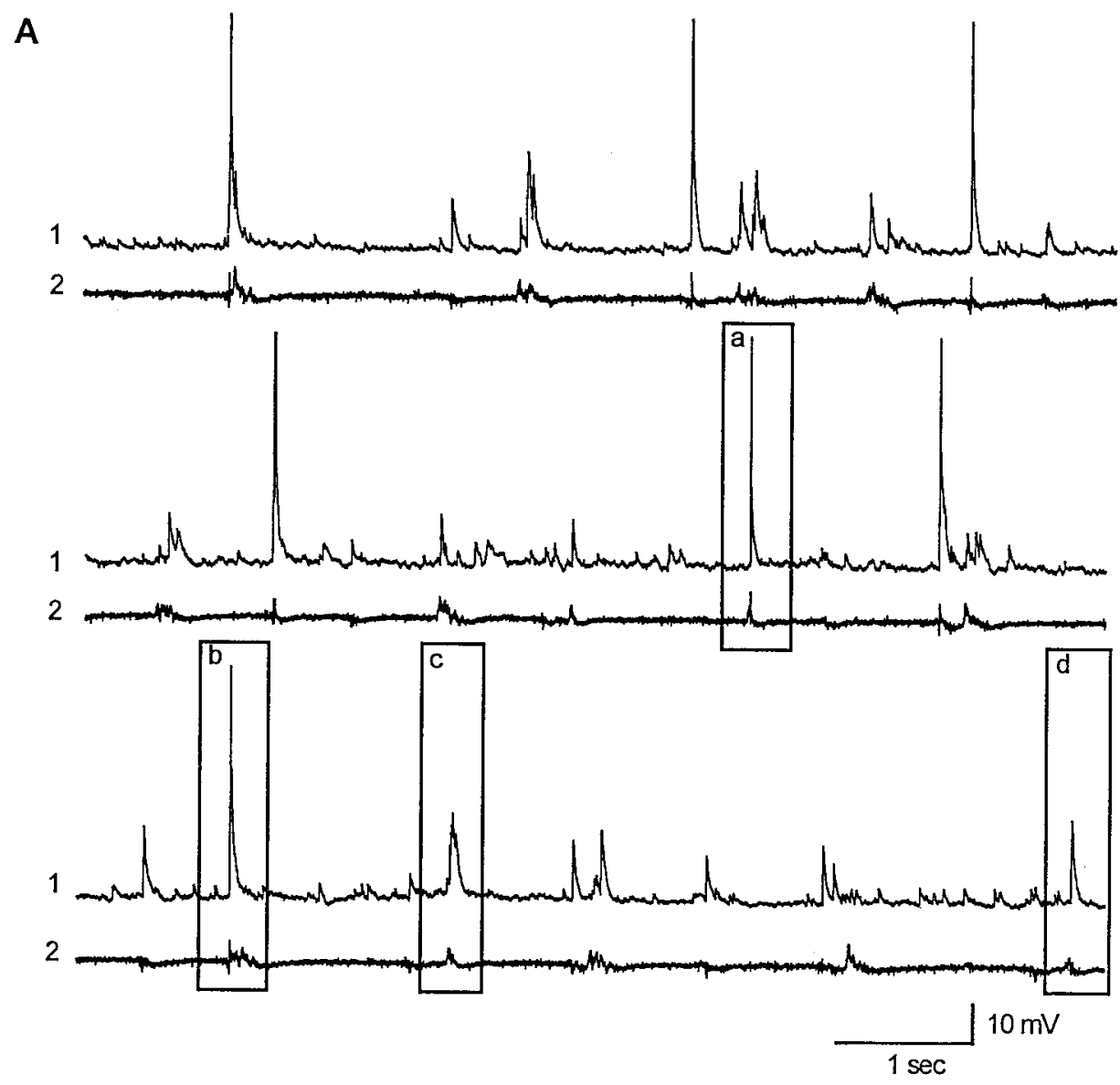

B
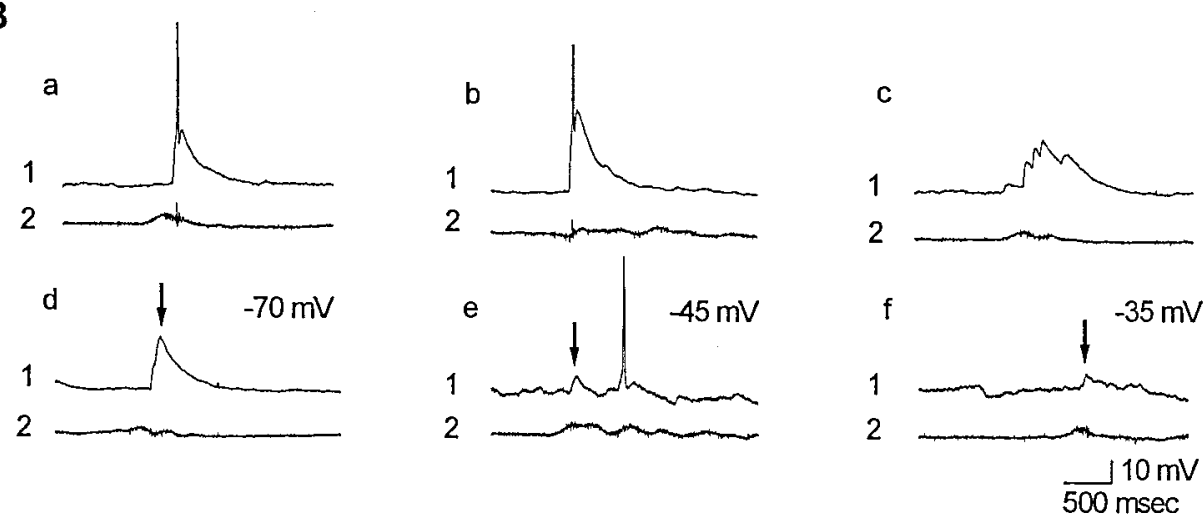

Figure 9. Barrages of synaptic potentials and resulting action potentials are recorded in CA3 pyramidal cells coincident with extracellular minibursts. $A$, Representative whole-cell recordings (traces 1) and extracellular field recordings (traces 2) from hippocampal slices taken during TTX infusion. Selected events outlined by boxes are shown at a faster time base in $B a-B d$. Synaptic events (arrows) are shown at three different holding potentials in $B d-B f$. Recordings were made from slices of ventral hippocampus taken immediately after 2 weeks of TTX infusion of dorsal hippocampus. For this cell, the resting membrane potential was $-65 \mathrm{mV}$, input resistance was 150 $\mathrm{M} \Omega$, the holding potential was $-70 \mathrm{mV}(A$, $B a-B d)$, and spike amplitude was $68 \mathrm{mV}$. were depolarizing above the reversal potential for $\mathrm{GABA}_{\mathrm{A}}$ IPSPs. Traces in Figure $9 B d-B f$ show representative recordings. At holding potentials of -45 and $-35 \mathrm{mV}$, depolarizing synaptic potentials were observed coincident with minibursts. As expected, the amplitudes of these events were reduced because of a reduction in cation driving force.

These recordings suggest that bursts of large EPSPs underlie minibursts seen in epileptic rats. In addition to EPSPs, other cells received mixtures of synaptic potentials. In some instances, pyramidal cells revealed barrages of synaptic potentials that phasically depolarized and then hyperpolarized the cell. Whole-cell recordings from five CA3 pyramidal cells from three ACSFinf used littermate controls failed to demonstrate similar bursts of synaptic potentials, and no minibursts were present in extracellular field recordings.
A chronic infusion of TTX could conceivably result in a compensatory upregulation of sodium action potentials channels. Thus, a resulting increase in the intrinsic neuronal excitability of individual neurons could underlie the hyperexcitability of assemblies of CA3 pyramidal cells demonstrated in Figure 9. To explore this possibility, passive and active membrane properties of individual pyramidal cells in epileptic rats were compared to those of ACSF-inf used rats. Table 2 shows the resting membrane potential, input resistance, and measures of action potential amplitude and duration in experimental rats were very similar to that of controls. Recordings in Figure 10 compare intrinsic bursts in these cells. In traces 1 , the first action potential of the bursts shown in traces 2 and 3 are depicted at a faster time base. The waveforms of these spikes are very comparable. Moreover, the duration of the intrinsic bursts and average number of spikes in 
Table 2. Comparison of the neurophysiological properties of CA3 pyramidal cells in experimental and control rats

\begin{tabular}{lcc} 
& Control & Experimental \\
\hline$n$ & 4 & 5 \\
$V_{\mathrm{m}}, \mathrm{mV}$ & $-65 \pm 4.2$ & $-66 \pm 3.6$ \\
$R_{\mathrm{m}}, \mathrm{M} \Omega$ & $180 \pm 21$ & $161 \pm 14.6$ \\
Spike amp, mV & $73.9 \pm 2.7$ & $80.4 \pm 3.2$ \\
Spike duration, $1 / 2$ amplitude, msec & $1.3 \pm .01$ & $1.1 \pm .03$ \\
Intrinsic burst duration, msec & $60.3 \pm 1.4$ & $63.2 \pm 3.1$ \\
Number of spikes per burst & $2.5 \pm 0.5$ & $2.3 \pm 0.3$
\end{tabular}

$\overline{n=\text { number of cells. Data are presented as mean } \pm \text { SEM. Differences between all }}$ measures made in saline-infused (control) and TTX-infused (experimental) rats were not significant $(p>0.05)$.
A

CONTROL

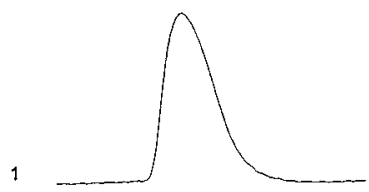

$$
1
$$
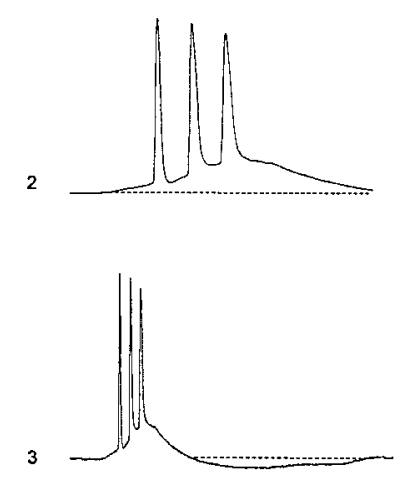

B

EXPERIMENTAL

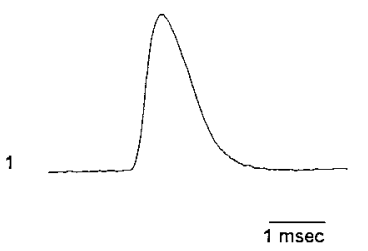

2
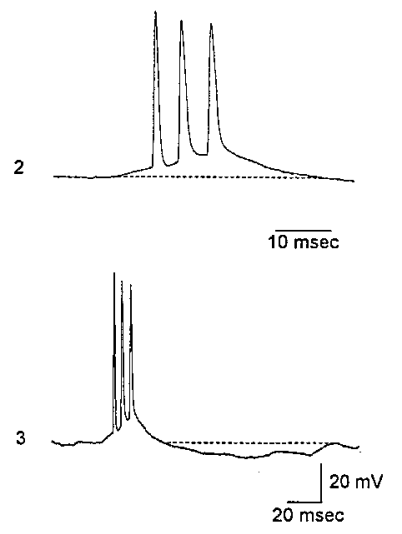

Figure 10. Comparison of spontaneous intrinsic bursts recorded in slices from control $(A)$ and experimental $(B)$ rats. Traces 1 compare the waveform of the first action potential in the intrinsic bursts shown below in traces 2 and 3 at slower time bases. The duration of the depolarizing envelope that underlies the burst discharge was similar in the two treatment groups. Postburst afterhyperpolarization are evident in traces 3 . Resting membrane potential and input resistance: $A,-68 \mathrm{mV}, 180 \mathrm{M} \Omega$; $B, 70 \mathrm{mV}, 200 \mathrm{M} \Omega$. Age: control, $31 \mathrm{~d}$; experimental, $25 \mathrm{~d}$.

these discharges did not differ in experimental and control animals (Table 2). In CA3 neurons from experimental rats, the intrinsic bursts were followed by a prominent afterhyperpolarization, which can also be seen in neurons from control animals (Fig. $10 \mathrm{~A}$, traces 3 ). Thus, taken together, whole-cell recordings suggest abnormal network activity is likely produced by hyperinteractive CA3 pyramidal cells and may result from enhanced recurrent excitatory synaptic transmission in TTX-infused hippocampus.

\section{DISCUSSION}

The CA3 region of the hippocampus from 2- to 3-week-old rats has a marked propensity to generate electrographic seizures (Swann and Brady, 1984). When hippocampal slices are taken from rats during this critical period and exposed to $\mathrm{GABA}_{\mathrm{A}}$ receptor antagonists, prolonged electrographic seizures occur.
Such induced discharges are rarely observed at younger or older ages. In the past, postnatal weeks 2 and 3 have been referred to as the "critical period of hippocampal CA3 network excitability." This critical period likely differs from critical periods in the development of other neural networks in the brain. The maturation of neurons and the assembly of networks depend on the birth dates of cells and rates of neuronal differentiation. These can differ significantly between regions and cell types.

Results of numerous electrophysiological experiments (Brady and Swann, 1988; Smith et al., 1995; Gomez Di Cesare et al., 1997) suggest recurrent excitatory synaptic transmission within local assemblies of CA3 hippocampal neurons contribute importantly to enhanced seizure susceptibility in early life. Developmental studies of recurrent excitatory axonal arbors emanating from single CA3 pyramidal cells support this notion. During the first postnatal week and before the critical period of enhanced network hyperexcitability, few axons arise from CA3 pyramidal cells. However, by the middle of week 2, extensive arbors have grown. By adulthood, half of axonal branches are pruned (Gomez-Di Cesare et al., 1997). Thus, this anatomical remodeling of axonal arbors correlates with and has been proposed to underlie the age-dependent changes in seizure susceptibility (Swann, 1995).

Numerous studies of developing afferent projections and local circuit axon arbors have suggested that the developmental remodeling of axon arbors is regulated by neuronal activity (Goodman and Shatz, 1993; Katz and Shatz, 1996). Thus, it is reasonable to suspect that blockade of neuronal activity during early life could at least enhance seizure susceptibility later in life by preventing developmental axonal remodeling. Support for this idea comes from the studies of audiogenic seizures in rats. A transient hearing loss during postnatal weeks 2 and 3 has been shown to lead a permanent susceptibility of rats to sound-triggered seizures and an apparent persistent ascending hyperinnervation of the inferior colliculus that characterizes early life (Pierson and Swann, 1988, 1991; Pierson and Snyder-Keller, 1994). In this regard, it is important to mention that infants and young children that are visually deprived because of a variety of clinical conditions commonly have prominent interictal spikes in occipital cortex (Kellaway, 1989). Based on these observations, we anticipated that the marked propensity of area CA3 for electrographic seizures, seen in postnatal weeks 2 and 3, would be extended into adulthood by TTX infusion.

\section{The emergence of a chronic epilepsy}

The recurrent seizures that developed because of local TTX infusion were unexpected. Originally, we anticipated that when hippocampal slices were taken from these adult rats they might generate seizure-like discharges when exposed to $\mathrm{GABA}_{\mathrm{A}}$ receptor antagonists. Instead, rats displayed spontaneous behavioral and electrographic seizures in the absence of convulsant drugs and generated interictal discharges and seizures even as TTX infusion was ongoing. Numerous aspects of these observations require discussion. The first is the age when activity blockade is most effective. Results suggest that inf usion of TTX between days 10 and 17 is essential for producing the effects described. However, epileptogenesis is most dramatic when infusion begins on days 10-12. It is possible that initiating TTX infusion during week 1 of postnatal life could be even more effective in producing a chronic epilepsy. However, such experiments would be difficult because of the fragility of the neonatal skull and the size of the osmotic minipumps. Secondly, the duration of activity blockade is 
likely another important parameter. Abnormal discharges were first observed 2 weeks after the initiation of TTX infusion. It is conceivable that withdrawal of TTX after short periods of infusion (e.g., 1 week) could have produced the same effect. This issue can be addressed experimentally, but has yet to be undertaken. A third issue is how does blockade of neuronal activity produce hyperexcitable networks in ventral hippocampus when TTX is infused in the dorsal hippocampus. Such hyperinteractivity could result from a lack of recurrent axon pruning. Axon arbors of CA3 pyramidal cells are not restricted to the laminae of the parent neuron but project widely within the hippocampus (Swanson et al., 1981; Amaral and Witter, 1989; Ishizuka et al., 1990; Tamamaki and Nojyo, 1991; Li et al., 1994). Thus, the lack of activity in the rich plexus of the "longitudinal associational bundle" arising from pyramidal cells in dorsal hippocampus could lead to the preservation of early-formed synapses in ventral hippocampus-simply as a result of a lack of competition. Lastly, we have assumed, as many others have (Stryker and Harris, 1986; Antonini and Stryker, 1993; Herrmann and Shatz, 1995) that the effects of TTX on developing neurons is via its ability to selectively block voltage-gated sodium channels. However, it is possible that TTX may have other unrecognized effects that contribute to the generation of seizures.

A surprising feature of the seizures observed in TTX-infused rats was their progression over time. Focal interictal discharges in ventral hippocampus rapidly evolved to a multifocal disorder (Fig. 5). Over subsequent months, seizure durations increased from an average of $3.0 \pm 0.2 \mathrm{sec}$ to $89 \pm 10 \mathrm{sec}$. It seems plausible that multifocal discharging may result from the activity of single epileptic foci. Indeed, in infant rats, a unilateral intrahippocampal injection of the convulsant, tetanus toxin, has been shown to result in multifocal epilepsy (Lee et al., 1995; Anderson et al., 1997).

Why seizures progress in duration in adulthood is not understood. It is possible that the onset of early seizures primarily arises from the hyperexcitable tissue remote from the infusion site. Perhaps with time, CA3 pyramidal cells within the infused dorsal hippocampus, whose axon collaterals may not have remodeled, recover from blockade and begin to contribute to already hyperexcitable local networks, thereby exacerbating the epileptic state of these animals. Kindling may also underlie the progression of the seizures observed in these rats. Indeed, the recurrent seizures occurring in these animals are likely to have many consequences in both the developing and adult brain. For instance, in the tetanus toxin model of early-onset epilepsy, recurrent seizures are thought to result in mossy fiber sprouting (Anderson et al., 1999) and a loss of dendritic spines in CA3 hippocampal pyramidal cells (Jiang et al., 1998). Thus, in future studies, it will be of critical importance to dissociate the effects of blockade of neuronal activity from those of seizures.

\section{Synchronized discharging in area CA3: alternative mechanism}

Although the hypothesis that instigated the experiments reported here was that blockade of neuronal activity would prevent remodeling of recurrent excitatory axons and maintain hippocampal network hyperexcitability of infancy into adulthood, this may not be the mechanism responsible for seizures recorded in these rats. Blockade of neuronal activity could result in compensatory changes that result in sprouting of existing excitatory axonal arbors. While there is no evidence that such changes occur, recent studies in hippocampus, neocortex, and lateral geniculate nucleus have demonstrated an increase in dendritic spine density after suppression of synaptic activity (Dalva et al., 1994; Rocha and Sur, 1995; Kirov et al., 1999). On the other hand, blockade of neuronal activity in developing visual system either by TTX infusion or by visual deprivation has been reported to produce the opposite effect, a decrease in excitatory synapses at least as measured by NMDA receptor immunohistochemistry and Western blots (Catalano et al., 1997; Quinlan et al., 1999). However, in these studies, blockade of activity was initiated at earlier times in network formation. Different results may have been obtained by delaying treatment. Moreover, different mechanisms may be operant in hippocampus.

Another possible mechanism that could be responsible for the demonstrated network hyperexcitability in TTX-infused animals is an alteration in the intrinsic properties of pyramidal cells (Desai et al., 1999). Although our whole-cell recordings have not detected any dramatic changes in the intrinsic excitability of hippocampal pyramidal cells (Table 2, Fig. 10), more detailed studies are warranted. Enhancement of the $\mathrm{Ca}^{2+}$ current that underlies the intrinsic burst or suppression of the $\mathrm{K}^{+}$currents responsible for the prolonged afterhyperpolarization could conceivably produce hyperexcitable CA3 pyramidal cells and epileptiform activity. In this regard, it is important to note that Niesen and Ge (1999) have reported epileptiform activity in hippocampal slice cultures after a 1 week exposure to TTX. An enhancement of intrinsic excitability via an upregulation of T-type $\mathrm{Ca}^{2+}$ channels has been suggested to contribute to these discharges.

A third potential mechanism for the production of chronic seizures demonstrated in this model is a suppression of synaptic inhibition caused by abnormal development of GABAergic interneurons. Experiments conducted have not specifically address this issue. Finally, our in vitro slice studies have focused on the infused hippocampus. It is entirely possible that different mechanisms underlie the epileptiform discharges that arise from the independent foci in contralateral hippocampus.

\section{REFERENCES}

Amaral DG, Witter MP (1989) The three-dimensional organization of the hippocampal formation: a review of anatomical data. Neuroscience 31:571-591.

Anderson AE, Hrachovy RA, Swann JW (1997) Increased susceptibility to tetanus toxin-induced seizures in immature rats. Epilepsy Res 26:433-442.

Anderson AE, Hrachovy RA, Antalffy BA, Armstrong DL, and Swann JW (1999) A chronic focal epilepsy with mossy fiber sprouting follows recurrent seizures induced by intrahippocampal tetanus toxin injection in infant rats. Neuroscience 92:73-82.

Antonini A, Stryker MP (1993) Development of individual geniculocortical arbors in cat striate cortex and effects of binocular impulse blockade. J Neurosci 13:3549-3573.

Brady RJ, Swann JW (1988) Suppression of ictal-like activity by kynurenic acid does not correlate with its efficacy as an NMDA receptor antagonist. Epilepsy Res 2:232-238.

Catalano SM, Chang CK, Shatz CJ (1997) Activity-dependent regulation of NMDAR1 immunoreactivity in the developing visual cortex. J Neurosci 17:8376-8390.

Chiaia NL, Fish SE, Bauer WR, Bennett-Clarke CA, Rhoades RW (1992) Postnatal blockade of cortical activity by tetrodotoxin does not disrupt the formation of vibrissa-related patterns in the rat's somatosensory cortex. Brain Res Dev Brain Res 66:244-250.

Chiaia NL, Fish SE, Bauer WR, Figley BA, Eck M, Bennett-Clarke CA, Rhoades RW (1994) Effects of postnatal blockade of cortical activity with tetrodotoxin upon the development and plasticity of vibrissarelated patterns in the somatosensory cortex of hamsters. Somatosens Mot Res 11:219-228.

Dalva MB, Ghosh A, Shatz CJ (1994) Independent control of dendritic 
and axonal form in the developing lateral geniculate nucleus. J Neurosci 14:3588-3602.

Desai NS, Rutherford LC, Turrigiano GG (1999) Plasticity in the intrinsic excitability of cortical pyramidal neurons. Nat Neurosci 2:515-520.

Galvan CD, Hrachovy R, Smith KL, Swann JW (1998) Intrahippocampal infusion of TTX during a critical period of development produces a chronic focal epilepsy in the rat. Soc Neurosci Abstr 24:1932.

Gomez-Di Cesare CM, Smith KL, Rice FL, Swann JW (1997) Axonal remodeling during postnatal maturation of CA3 hippocampal pyramidal neurons. J Comp Neurol 384:165-180.

Goodman CS, Shatz CJ (1993) Developmental mechanisms that generate precise patterns of neuronal connectivity. Cell 72/Neuron 10 [Suppl]:1-20.

Herrmann K, Shatz CJ (1995) Blockade of action potential activity alters initial arborization of thalamic axons within cortical layer 4. Proc Natl Acad Sci 92:11244-11248.

Ishizuka N, Weber J, Amaral DG (1990) Organization of intrahippocampal projections originating from $\mathrm{CA} 3$ pyramidal cells in the rats. J Comp Neurol 295:580-623.

Jiang M, Lee CL, Smith KL, Swann JW (1998) Spine loss and other persistent alterations of hippocampal pyramidal cell dendrites in a model of early-onset epilepsy. J Neurosci 18:8356-8368.

Johnston D, Brown TH (1981) Giant synaptic potential hypothesis for epileptiform activity. Science 211:294-297.

Katz LC, Shatz CJ (1996) Synaptic activity and the construction of cortical circuits. Science 274:1133-1138.

Kellaway P (1989) Introduction to plasticity and sensitive periods. In: Problems and concepts in developmental neurophysiology (Kellaway P, Noebels JL, eds), pp 3-28. London: The John Hopkins UP.

Kirov SA, Sorra KE, Harris KM (1999) Slices have more synapses than perfusion-fixed hippocampus from both young and mature rats. J Neurosci 19:2876-2886.

Lee CL, Hrachovy RA, Smith KL, Frost JD, Swann JW (1995) Tetanus toxin-induced seizures in infant rats and their effects on hippocampal excitability in adulthood. Brain Res 677:97-109.

Li XG, Somogyi AY, Busaki G (1994) The hippocampal CA3 network: An in vivo intracellular labeling study. J Comp Neurol 339:181-208.

Miles R, Wong RKS (1983) Single neurons can initiate synchronized population discharge in the hippocampus. Nature 306:371-373.

Miles R, Wong RKS (1987) Inhibitory control of local excitatory circuits in the guinea-pig hippocampus. J Physiol (Lond) 388:611-629.

Neisen CE, Ge S (1999) Chronic epilepsy in developing hippocampal neurons: electrophysiologic and morphologic features. Dev Neurosci 21:328-338.

Pierson M, Snyder-Keller A (1994) Development of frequency-selective in inferior colliculus of normal and neonatally noise-exposed rats. Brain Res 636:55-67.
Pierson MG, Swann JW (1988) The sensitive period and optimum dosage for induction of audiogenic seizure susceptibility by kanamycin in the Wistar rat. Hear Res 32:1-10.

Pierson MG, Swann JW (1991) Ontogenetic features of audiogenic seizure susceptibility induced in immature rats by noise. Epilepsia 32:1-9.

Quinlan EM, Philpot BD, Huganir RL, Bear MF (1999) Rapid, experience-dependent expression of synaptic NMDA receptors in visual cortex in vivo. Nat Neurosci 2:352-357.

Rocha M, Sur M (1995) Rapid acquisition of dendritic spines by visual thalamic neurons after blockade of $N$-methyl-D-aspartate receptors. Proc Natl Acad Sci USA 92:8026-8030.

Smith KL, Szarowski DH, Turner JN, Swann JW (1995) Diverse neuronal populations mediate local circuit excitation in area CA3 of developing hippocampus. J Neurophysiol 74:650-672.

Sokoloff L, Reivich M, Kennedy C, DesRosiers MH, Patlak CS, Pettigrew KD, Sakurado O, Shinohara M (1977) The $\left({ }^{14} \mathrm{C}\right)$ deoxyglucose method for the measurement of local cerebral glucose utilization: theory, procedure, and normal values in the conscious and anesthetized albino rat. J Neurochem 28:897-916.

Stryker MP, Harris WA (1986) Binocular impulse blockade prevents the formation of ocular dominance columns in cat visual cortex. J Neurosci 6:2117-2133.

Swann JW (1995) Synaptogenesis and epileptogenesis in developing neural networks. In: Brain development and epilepsy (Schwartzkroin PA, Moshe SL, Noebles JL, Swann JW, eds), pp 195-233. New York, Oxford UP.

Swann JW, Brady RJ (1984) Penicillin-induced epileptogenesis in immature rat CA3 hippocampal pyramidal cells. Dev Brain Res 12:243-254.

Swann JW, Brady RJ, Friedman RJ, Smith EJ (1986) The dendritic origins of penicillin-induced epileptogenesis in CA3 hippocampal pyramidal cells. J Neurophysiol 56:1718-1738.

Swann JW, Smith KL, Brady RJ (1993) Localized excitatory synaptic interactions mediate the sustained depolarization of electrographic seizures in developing hippocampus. J Neurosci 13:4680-4689.

Swanson LW, Sawchenko PE, Cowan WM (1981) Evidence for collateral projections by neurons in Ammon's horn, the dentate gyrus, and the subiculum: A multiple retrograde labeling study in the rat. J Neurosci 1:548-559.

Tamamaki N, Nojyo Y (1991) Crossing fiber arrays in the rat hippocampus as demonstrated by three-dimensional reconstruction. J Comp Neurol 303:435-442.

Tessier-Lavigne M, Goodman CS (1996) The molecular biology of axon guidance. Science 274:1123-1133.

Weisel TN, Hubel DH (1963) Single-cell responses in striate cortex of kittens deprived of vision in one eye. J Neurophysiol 26:1003-1017. 